\title{
The Current Status of Patient Privacy
}

\author{
Na Wang \\ Department of Anesthesiology \\ The First Hospital of Jilin University \\ Changchun, China \\ wangna080613@163.com
}

\author{
Jinguo Wang (corresponding author) \\ Department of Urology \\ The First Hospital of Jilin University \\ Changchun, China \\ wangjinguolily@163.com
}

\begin{abstract}
To actively protect the patient's right of privacy is beneficial to the realization of freedom and development, to achieve peace and independence of the individual. Based on the realities and situations of our country and though learning foreign experiences, suggestions are provided. Patients' right of privacy embodies domination of their privacy. Patients with privacy can have enough personal space to give full play to their personality.
\end{abstract}

Keywords—Patient, privacy, doctor

\section{INTRODUCTION}

Patient privacy is a special part of the natural person's privacy; accordingly, patient's right to privacy is a special type of general privacy. Patients is a natural person, the first to accept or a medical disease diagnosis and treatment, medical institutions must embody the privacy in relation to their body or disease. But the patients' right to privacy should be an extension of the concept of privacy, so it inevitably has the general characteristics of the right of privacy. To really delve into the connotation of patients' right of privacy and its uniqueness, must be traced back to the first research the related issues of privacy and privacy.

\section{Patient PRIVACY}

With the highest value in the contemporary society, personality, personality interests, is regarded as the highest value and the development of human rights has become a target of modern human rights movement and the basic idea. In order to protect the patients' right of privacy individual spiritual pursuit is the goal [1]. However, with the continuous development of market economy in our country, and prosperity, science and technology and the rapid development of information communication, people should have privacy is facing more and more likely to be infringed. Patients of privacy protection consciousness awakening, citizens because of privacy is being violated and Sue to the people's court to claim damages case more and more, and the trend of rising year by year. Patients right of privacy is a concrete personality right, is the basic dignity of patients as a person. And implementing medical behavior in the medical staff have to visit and contact with the patient's privacy, to disease diagnosis and treatment, to explore and pursue the psychological as well as contact and check of the organs and so on, all these medical behavior suggests that the health care industry has always been a sensitive area of the privacy infringement. That patients enjoy privacy than ordinary citizens' right of privacy is more vulnerable to invasion, even exist in some people's mind "in front of the medical staff, patients don't enjoy privacy" misconceptions. Privacy is a personal dignity line of defense, is "the testimony of the bitterness of the person's behavior" [2].

\section{A. Patients' right of privacy embodies domination of their privacy.}

In fact, whether in China or abroad, protect the patient's privacy is always the doctor medical ethics that should be followed when practicing medicine. From around the world to the patients' rights provisions of the specific content of each are not identical, but whether the world medical association published the declaration of the rights of patients, or countries to enact the law to protect patients' rights, for the patient privacy protected is their common characteristic. Patients right of privacy has ethical, sacred and inviolable as a kind of private right, the exercise and enjoy the legal range should be based on principles of civil autonomy, others can't sabotage and interference. But the protection of patients' right of privacy, there are exceptions. When patients exercise of the right of privacy is beyond the private sector and into the public domain, it becomes not only belongs to the person enjoy privacy interests. At this point, the exercise of patients' right of privacy and public right to know, doctor's right to know, the third person's right to know, and even their own life [3]. How about the conflict of rights protection and carried out for the rights to coordinate the interests behind hidden became a little troublesome problem that must be addressed. Human consciousness and ideas about privacy, it is when people out of the animal kingdom and become one, from the human sense of shame and germination. In the early stage of human society, people begin to use animal skins, leaves cover some parts of the body, which suggests that the privacy of the existed concepts of ancient times.

A type of patients right of privacy is the right of privacy, the general characteristics of it, of course, have the right of privacy, such as main body, object characteristics and dominant, these features above analysis, is no longer here. Leave the medical activities of the special environment of patients' right of privacy, and the particularity of the medical profession and the right to privacy of public figures, the privacy rights of vulnerable groups and other general privacy is different, and has their unique characteristics. 


\section{B. The content of patients' right of privacy of relatively concentrated}

Patients' right of privacy is the patients to medical institutions for medical treatment service, and health providers are signed after the medical contract. So the protection content of patients' right of privacy has the characteristics of the relatively specific, limited to patients in medical treatment activity revealed by the prescriptions of legal learn all kinds of information, transaction and domain, etc. [4]. But this is not the same as for the patients privacy content include only closely with medical treatment activity phase information, such as the patient's body secret, disease information, etc., and other information provided by not including patients, such as the patient's name, phone number, home address, and other general personal situation [5,6]. The scholar thinks, generally only in patients as general privacy protection to the natural person to enjoy, not unique to patients' right of privacy protection. To this, the author did not agree with, although this kind of personal information and disease diagnosis and treatment in patients with no direct link, but it is required to register the patient medical record information when necessary and facilitating the prescriptions tracking and study the disease

The treatment effect and do a good job later. Patients and medical behavior is directly related to the data being compromised, their personal information is often violated at the same time, and they tend to have oneness, sometimes difficult to distinguish [7]. So, this kind of patients associated with medical treatment activity indirectly prescriptions got by the legal, privacy is also obviously is also one of the contents of the patients privacy should be protected.

\section{The particularity of the exercise of patients' right of privacy way}

Natural person in exercise the right of privacy, both sides tend to express way, through the form of a contract of privacy use to clear the scope of the agreement. But the patient's right to privacy in the mode of exercise has its own uniqueness. The author believes that the patients or their family members to give up their part can be divided into two kinds of privacy. Is a kind of implied consent [8]. Patients to the hospital to consent to the fact that it has implied to be responsible for the diagnosis and treatment of medical personnel can be personal privacy about reasonably. Here are limited to the medical staff have a direct contact with diagnosis and treatment of medical personnel, including the patient's attending physician, need consultation of experts and the implementation of inspection, the injection treatment measures such as nurses, shall not be arbitrarily extended. Patients are widely accepted implied with cordiality is not only the need of diagnosis and treatment, but also to help medical staff to fully understand the condition and appropriate treatment, the condition of early rehabilitation. The other is a express consent. Have direct contact with diagnosis and treatment outside the scope of other personnel must go through the express permission of the patients or their family members can be understanding and patient privacy for the disease. When it comes to patients under the condition of private parts, especially must be subject to the consent of the patients or their family members. Other people include patients attending physician here other than physicians, hospital internship, other patients to the hospital, and even accompanied by relatives of the patients in the case of necessary condition of physicians in clinical or consent of the patients.

\section{The asymmetry of the patient's privacy licensor}

Licensor and understand Right or Right (the Right to Know), refers to a person has the Right to Know what he ought to Know. Right to know in general can be divided into power, social right and right to know personal information data. Privacy licensor and referred to in this article refers to the individual information data's right to know, its basic meaning is refers to the natural person in accordance with the law shall have the right to understand information about his various aspects. Due to the particularity of the doctor-patient relationship, doctor holds the patients of patients, medical conditions and other personal important information; these are all important privacy information of patients. And the medical staff usually does not take the initiative to tell this information to patients, sometimes even no need to tell all the learned information to patients, which creates a doctor-patient information asymmetry of both sides. On the way to grasp the information, medical staff are usually in a strong position, and the patient's privacy licensor tend to be ignored, sometimes even the opportunity of defense was deprived. In recent years, more and more of the causes of medical disputes happened is that patients want to know about medical records in relation to their diseases is being rejected without reason, the patients privacy licensor cannot be realized. Patients because of their licensor is not respected, namely in the hospital can't consumption for hospital, to medical institutions to court.

\section{E. Vulnerable to invasive of patients' right of privacy}

Although medical behavior is to save the patients' life and health for the purpose, but USES the methods of diagnosis and treatment, all with invasive and damaging to the body and it is easy to understand in the process of diagnosis and treatment to the patients' privacy. Medical staff will often ask the patient's disease characteristics, medical history, family heredity, at ordinary times life habit, for patients with parts of the body or body fluids such as blood, waste for regular inspection and so on, these can learn about the patient's privacy. Based on medical staff and patients trust and rely on, is also a need to treat their disease, and must give a part of private information to the medical staff, agree with its necessary for your body check. This makes in medical activities, develop party often in a passive position. Patients normally it is difficult to accurately define medical workers' right to know, for the specific scope of individual patients even think, let the medical staff know their own privacy, the more the more favorable for disease treatment. For medical member of spying on the defenseless, the action of heart, and often know all speak to the question. This objectively caused the medical staff with easy access to the patient's privacy information. In reality, there is a part of the quality of medical staff, to strengthen legal consciousness, patients right of privacy is easy to be infringed.

Patients with a special type of privacy are the right of privacy, through the analysis of the front of theoretical problems with a basic understanding of patients' right of privacy [9]. However, theory and practice is linked together, 
the law is the purpose of the patients privacy in order to protect the patients privacy interests in reality. In reality, the level of patient privacy protection in China, the patient's privacy interests are violated what situation, what are the reasons? These need us to analysis and research on it.

Protect the patient's right to privacy is a medical institution and its medical personnel of a legal obligation. But from the current overall situation analysis, patients in the doctor-patient relationship in a weak position, by the violation of patients' right of privacy. Privacy is being violated in medical treatment activity, patients can be roughly divided into the following several types.

Now many of the city level of first-class hospital, affiliated hospitals of medical universities and colleges, in particular, are responsible for the practical work of medical teaching tasks, organization medical interns in hospital outpatient department, clinical laboratory, the inpatient department internship, interns during the internship can see the body like practicing doctors, medical records, such as X-ray patient privacy, also can see the process of examination and operation patients. Clinical teaching activity is arranged in the hospital, the patient to the hospital for medical treatment is actually acted as a "live aid". In almost every component in the medical teaching practice there is the violation of patients' right of privacy, and the practice of hospital is completely ignored the existence of patients right of privacy, not to mention the protection. No consent of the patients for medical teaching in the process of advance hospital also has their own views [10]. In order to promote the development of medicine and train excellent medical personnel, some hospitals bear the medical clinical teaching work, so the clinical practice teaching work is a statutory duties and obligations of the medical institutions. Medical activities of the professional and high technical determines for is about to become a qualified medical personnel, medical clinical practice link is indispensable.

Medicine is the most practical discipline; the improvement of medical technology is indispensable to a doctor of the accumulation of clinical experience. Enable the same disease and the patient's individual differences in different patients tend to reflect the different clinical symptoms. All these need the doctor to accumulate in the medical practice and master. Interns only amassed ample internship experience to become qualified medical personnel. However, in order to improve the level of interns clinical technology does not mean that patients will have to sacrifice their privacy [11]. On the one hand, the patients received medical services aim is to cure the disease, restore health. Patients to give up part of the body of the right of privacy is confined to cure diseases, does not include interns. Interns are not a doctor. On the other hand, the patients did not cooperate with medical practice teaching obligations. The doctor-patient relationship only prescriptions and suffers from two side of the main body, and there is no room for interns intervention, therefore, patients are under no obligation bear teaching specimens. Although clinical teaching undertakes the important task of training qualified medical personnel, but not as a justification of patients' right of privacy infringement. Prescriptions are not subject to consent by the patient to serve as a clinical teaching "live aid" inevitably cause harm to the patient's dignity and mental health, and is unfavorable to the treatment of diseases. In fact, most patients are able to understand the clinical teaching, and the patient is only require respect for their basic rights, told in advance and let the patient have a choice, not only can ensure the normal conduct of teaching, and also can reduce the occurrence of medical disputes.

\section{CONCLUSION}

Due to the traditional system for a long time and the effect of nursing mode, medical personnel legal consciousness, lack of consciousness of patients' right of privacy protection. On the one hand, in the traditional dominant patriarchal concept of doctor-patient relationship, the relationship between doctors and patients is like the relationship between parents and children, the doctor may decide to all patients, with absolute authority. Many medical staff still think learn more patient's privacy is in the process of diagnosis and treatment for the purpose of saving lives, also for the sake of patients, the patients in front of the medical staff about their privacy should not be retained, also need not retained. On the other hand, during the period of planned economy era of health care system, "seller's market" dominant, hospitals and medical personnel lack of competition and sense of service, and health providers to gain the initiative in the medical information and treatment of disease, patients of extreme lack of medical knowledge, this in fact resulted in the unequal status between both doctors. Different from the past, people now legal awareness and equality awareness are increasing, the status of the patients' right of privacy has also been greatly improved. However, there are still many medical personnel way of thinking to stay in the past to "rescue" the identity of the treated patients, the patients privacy enjoyed by the lack of enough attention, some even ignore, cold attitude to treat the patient's privacy, do not take the patient to protect the privacy of their desire. In addition, in the daily health work, there are also some medical personnel in violation of state health laws and regulations, in violation of the operating rules of medical treatment, patients right of privacy and other human rights violations, in this case the doctor-patient relationship nervous and frequent medical disputes is unavoidable.

\section{REFERENCES}

[1] Shan L, Li Y, Ding D, Wu Q, Liu C, Jiao M, Hao Y, Han Y, Gao L, Hao J, Wang L, Xu W, Ren J. Patient Satisfaction with Hospital Inpatient Care: Effects of Trust, Medical Insurance and Perceived Quality of Care. PLoS One. 18;11(10):e0164366.Oct 2016.

[2] Valluri KA. Annals Graphic Medicine-Today's Doctor-Patient Relationship. Ann. Inte. Med. 4;165(7): W12. Oct 2016.

[3] Lv Zhaogong,wang xy,zhang jian.The doctor-patient relationship status quo,causes and countermeasures research:ten cities in China the doctorpatient relationship research. 2010

[4] Shen Fengping."A doctor"difficulty and high cost of the analysis of the causes and countermeasures. Journal of Chinese modern hospital management journal. 2010

[5] Wang Zhichao.The current doctor-patient conflict reasons of public policy analysis. 2012

[6] Stanley wang,Tian Kan.Our country the doctor-patient relationship status quo series. Journal of health soft science . 2009

[7] Lei Zhi Chun,Jiang Jilu.Discuss how to build a harmonious doctorpatient relationship. China's hospitals. 2006 
[8] Ming wang. Doctor-patient relations. 2008

[9] Astrong zhuang. The doctor-patient relationship, thinking and countermeasure introduction. 2007
[10] Hai TAO.The laws and regulations and professional medical work specification. 2008

[11] Zhao Bang Qin. Medical humanities. 2011 